\title{
Primary Pulmonary Hypertension in Children May Have a Different Genetic Background Than in Adults
}

\author{
EKKEHARD GRÜNIG, ROLF KOEHLER, GABRIEL MILTENBERGER-MILTENYI, \\ RAINER ZIMMERMANN, MATTHIAS GORENFLO, DERLIZ MERELES, KARLIN ARNOLD, \\ BARBARA NAUST, HEINRIKE WILKENS, ANDREAS BENZ, ALBRECHT VON HIPPEL, \\ HERBERT E. ULMER, WOLFGANG KÜBLER, HUGO A. KATUS, CLAUS R. BARTRAM, \\ DIETMAR SCHRANZ, AND BART JANSSEN
}

\begin{abstract}
Department of Cardiology, Angiology, and Pneumology [E.G., D.M., K.A., A.B., W.K., H.A.K.], University of Heidelberg, 69115 Heidelberg, Germany, Institute of Human Genetics [R.K., G.M.-M., B.N., A.v.H., C.R.B., B.J.], Department of Pediatric Cardiology [M.G., H.E.U.], Heidelberg University, 69120 Heidelberg, Germany, Pediatric Cardiology Center [R.Z., D.S.], University of Giessen, 35385 Giessen, Germany, Department of Pneumology [H.W.], University of Homburg, 66421 Homburg, Saar, Germany
\end{abstract}

\begin{abstract}
Mutations of the bone morphogenetic protein receptor II (BMPR2) gene on chromosome $2 \mathrm{q} 33$ can cause familial primary pulmonary hypertension (PPH) and may occur in $26 \%$ adult patients with sporadic disease. Other disease-related genes have been localized to chromosomes 2q31 (PPH2) and 12q13 (ALK1). The genetic background in affected children remains unclear. Thirteen children (age at diagnosis, 6 mo to $13 \mathrm{y}$; mean, $5.6 \pm$ 3.9 y) with invasively confirmed PPH were screened for $B M P R 2$ mutations using denaturing HPLC and sequence analysis. In addition, all children were scanned for BMPR2 deletions by Southern blot analysis. Pulmonary artery pressure was assessed using echocardiography at rest and during exercise in 57 family members of six infants. The six families were subjected to linkage analysis. None of the 13 children had a BMPR2 mutation or deletion. Linkage to chromosome 2 or 12 could not be confirmed in any of the families investigated. In all assessed families, both parents of the index patient and/or members of both branches revealed an abnormal pulmonary artery systolic
\end{abstract}

\section{ABSTRACT}

pressure (PASP)-response to exercise. $\mathrm{PPH}$ in children may have a different genetic background than in adults. We postulate a recessive mode of inheritance in a proportion of infantile cases. (Pediatr Res 56: 571-578, 2004)
Abbreviations
ALK1, actin receptor-like kinase 1
BMPR2, bone morphogenetic protein receptor type II
DHPLC, denaturing high performance liquid chromatography
HHT, hereditary hemorrhagic teleangiectasia
IPPH, infantile primary pulmonary hypertension
LOD, logarithm of the odds for linkage
PASP, pulmonary artery systolic pressure
PH, pulmonary hypertension
PPH, primary pulmonary hypertension
SE, stress-Doppler-echocardiography
SSCP, single-strand conformation polymorphism

PPH is a progressive cardiopulmonary disorder that may occur at any age (1). In the American PPH registry, the mean age at onset was $36 \mathrm{y}$, with a female-to-male ratio of 1.7 to 1 (2). Whereas PPH is usually diagnosed in the fourth decade of life, it sometimes affects children in the infancy. Children with IPPH have been reported to show higher pulmonary artery pressures, vascular resistance, and cardiac index than adults

Received November 27, 2003; accepted April 26, 2004.

Correspondence: Ekkehard Grünig, M.D., Department of Cardiology and Pneumology, University of Heidelberg, INF 410, 69120 Heidelberg, Germany; e-mail: Ekkehard_Gruenig@med.uni-heidelberg.de

Supported by a grant from the Medical Faculty of the University of Heidelberg.

DOI: 10.1203/01.PDR.0000139481.20847.D0
$(3,4)$. They often present with severe symptoms like syncope or are thought to have epilepsy. Before the advent of long-term vasodilator therapy, the mean survival time was only 10 mo for children $<16 \mathrm{y}$ old (5), whereas this was $2.8 \mathrm{y}$ in adults (6). Medial hypertrophy of the small pulmonary vessels was the predominant finding in children (7). Furthermore, $>40 \%$ of children with PPH responded to calcium channel blockers (5) in contrast to $\leq 25 \%$ adult responders (8).

It has not been assessed yet whether genetic mechanisms lead to these clinical differences. Mutations in the $B M P R 2$ gene of chromosome 2q33 have been identified in adults with PPH (9-11) and occurred in approximately half of the familial cases with autosomal dominant inherited disease and in approximately $26 \%$ of apparently sporadic adult cases $(10,12)$. Fur- 
thermore, it is known that large $B M P R 2$ deletions can cause a severe phenotype with an early onset in infancy $(13,14)$. This has only been reported in two families so far.

In BMPR2 mutation-negative families with autosomal dominantly inherited $\mathrm{PPH}$, we found linkage to a more proximal locus on chromosome 2q31 $(15,16)$. PH has also been diagnosed in adults and children suffering from HHT with mutations of ALK1 (14).

Recently, we have demonstrated that more than $90 \%$ of family members who shared the BMPR2 mutation and/or the risk haplotype with the PPH patients showed an abnormal PASP (17). The main goal of this study was to assess if and in which proportion apparently sporadic PPH in children can be caused by BMPR 2 mutations.

The second aim was to analyze whether further family members of the affected children reveal clinical signs of PPH or HHT using noninvasive methods and, if this was the case, to analyze the mode of inheritance.

\section{METHODS}

Study population and design. Between February 1999 and October 2003, 13 consecutive nonrelated children $<14$ y with PPH were evaluated. In all patients, the diagnosis "manifest PPH" was confirmed by a cascade of clinical examination including heart catheterization and was made according to the World Health Organization criteria (18) by at least one experienced and, for $\mathrm{PH}$, specialized pediatric center. In 3 of the 13 index patients, diagnosis was further confirmed by lung histopathology. Children $<28 \mathrm{~d}$ of age were excluded. A detailed family history was obtained and a pedigree of at least three to four generations was constructed. All living relatives of patients and control subjects were invited for clinical assessment including a medical history, physical examination, and 12-lead ECG and echocardiography at rest and during supine bicycle exercise. In the relatives or controls with abnormal PASP during exercise, secondary reasons were excluded by further assessment including laboratory tests, chest roentgenography, pulmonary function tests, and measurement of arterial blood gases. In two family members with abnormal PASP response to exercise and impaired left ventricular function, left heart catheterization was performed and resulted in the diagnosis of coronary artery disease in one (family 3421 , I-3, Fig. 1) and dilated cardiomyopathy in the other (family 3421 , I-4). In all patients and relatives, blood samples were collected for genetic analysis.

The control group consisted of 86 healthy volunteers, without acute or chronic pulmonary or cardiac diseases and without known risk factors for $\mathrm{PH}$. The clinicians were blinded to the results of genetic analysis. The Ethics Committee of the Medical Faculty of the University of Heidelberg approved the protocol of this study, and the participants or their parents gave their written informed consent.

Right heart catheterization and test for vasoreactivity was performed in the index patients in the pediatric centers after premedication with diazepam under local anesthesia as described previously (19).
Stress-Doppler-echocardiography. Examinations were carried out at rest and during supine bicycle exercise (model 8420, KHL Corp; ER 900 EL, Ergoline, Bitz, Germany) as described previously $(16,17,20)$. Results of PASP $<35 \mathrm{~mm} \mathrm{Hg}$ at rest and $<40 \mathrm{~mm} \mathrm{Hg}$ during exercise were classified as normal. PASP $>35 \mathrm{~mm} \mathrm{Hg}$ at rest and $>40 \mathrm{~mm} \mathrm{Hg}$ during exercise was classified as abnormal. All recordings were analyzed again off-line in random order and in a blinded fashion.

Mutation analysis. The entire protein coding region of $B M P R 2$ and all intron/exon boundaries were investigated by DHPLC (WAVE, DNA-Sep Cartridge, Transgenomic, Omaha, $\mathrm{NE}$ ) in all index patients and their parents. The primers listed on our website (http://www.med.uni-heidelberg.de/humangen/ ger/humgen/pph-scl.htm) were used to amplify 16 gene fragments by PCR. For DHPLC analysis, basic conditions (at least two temperatures were tested per exon) were chosen using the WAVEMAKER software (Transgenomic; Version D7000 HSM) and the Stanford program (http://insertion.stanford.edu). The protocols were validated in a series of 82 adult $\mathrm{PPH}$ patients by comparing the DHPLC results with the sequencing data obtained for all exons. No false positives or false negatives were identified (data not shown). Because DHPLC can only be used to detect heterozygous mutations, a second analysis was performed using a mixture (1:1) of patient DNA with wild-type DNA. In case of detecting altered peaks on DHPLC, samples were sequenced using the BigDye Terminator Kit version 2.0 and the ABI 3100 sequencer (Applied Biosystems, Foster City, CA).

Southern blot analysis was performed using three BMPR2 probes (kindly provided by Prof. R. Trembath, Leicester, UK) covering exons $1-4,4-10$, and $11-13$ in all index patients. Seven micrograms of each genomic DNA sample was digested with the restriction endonuclease PstI, electrophoresed through a $0.8 \%$ TBE agarose gel, and transferred on a nylon membrane (Hybond $\mathrm{N}+$, Amersham Pharmacia Biotech AB, Uppsala, Sweden) using standard protocols. The UV cross-linked DNA was then hybridized overnight at $65^{\circ} \mathrm{C}$ with the labeled probes (random primed DNA labeling kit, Roche Molecular Biochemicals, Mannheim, Germany), and exposed to Kodak XOmat AR x-ray films (Eastman Kodak, Rochester, NY) for 1 wk.

Linkage analysis. DNA was extracted from peripheral blood using a standard salting-out procedure. The members of six families $(3783,3067,3385,3421,4133,6735)$ were genotyped for the microsatellite markers D2S335, D2S2307, D2S2314, D2S309, D2S346, D2S2289, and D2S307 from the PPH1 $(B M P R 2)$ and putative $\mathrm{PPH} 2$ region on chromosome 2 and for D12S1633, D12S368, and D12S325 representing the ALK1 region. LOD scores (logarithm of the odds for linkage) were calculated by the LINKAGE program package (21). Subjects with manifest PPH were classified as affected (phenocopy rate: $0.0001 \%$, disease allele frequency of 1 in 10,000). Relatives with a pathologic PASP-response to exercise (AR) were classified as affected in the dominant model and as unaffected in the recessive model (phenocopy rate: 15\%; penetrance: $99 \%$ ). Relatives unavailable for analysis, members suspected to have secondary causes of $\mathrm{PH}$, members with suspected (but unconfirmed) $\mathrm{PPH}$, and individuals with a PASP response of exactly 


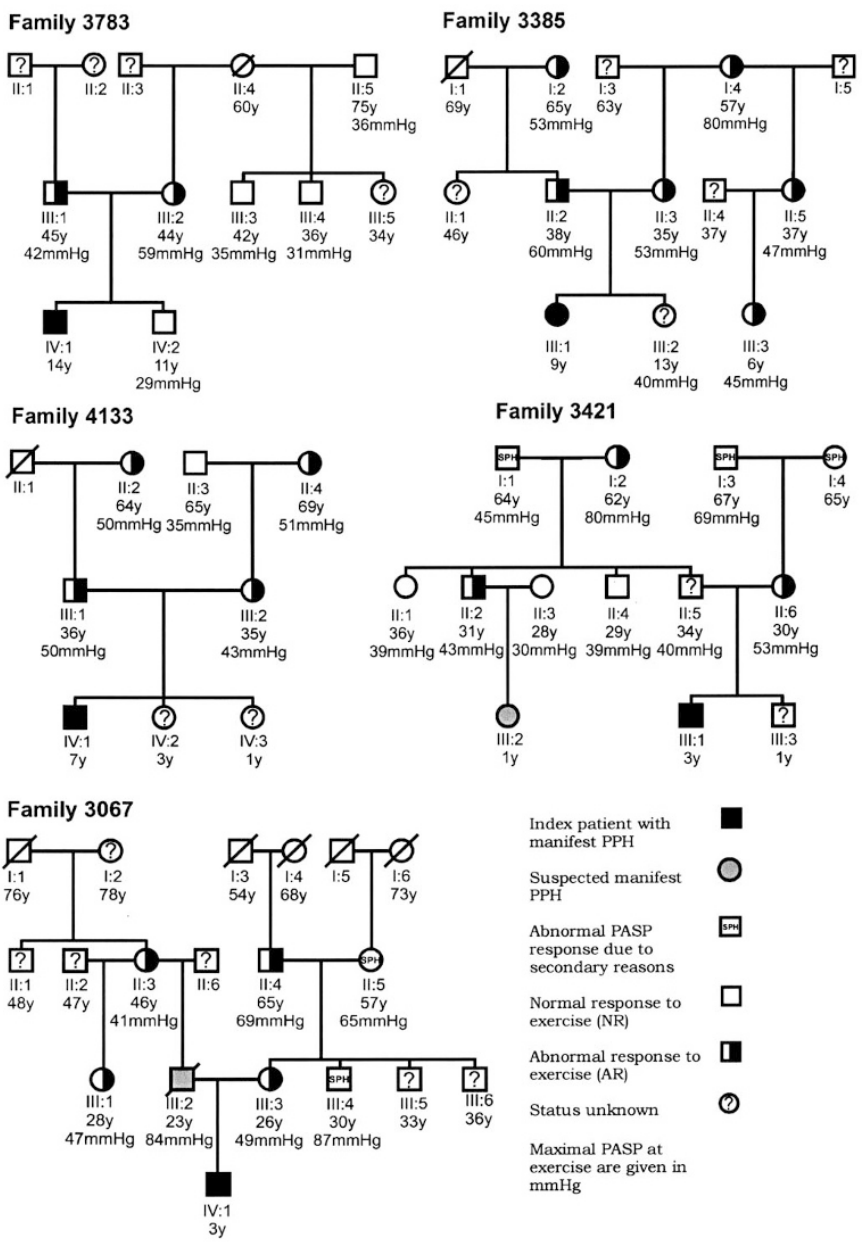

Figure 1. Family 3783: Index patient (IV-1) was the first baby of apparently healthy parents with birth at term by cesarean section because of breech presentation. Surgery of congenital hip dislocation was performed with 6 mo. A small atrial septal defect II was seen at the age of 20 mo and pulmonary hypertension was diagnosed. From invasive hemodynamic data there was no evidence that this septal defect could explain the $\mathrm{PH}$. As expected, the $\mathrm{PH}$ persisted after surgical atrial septal defect closure was performed. Ten years later he presented with signs of pneumonia. After a second cardiac catheterization, the diagnosis of PPH was made. On acute testing for pulmonary vascular reactivity there was no response to oxygen, nitric oxide, or inhaled iloprost. Oral beraprost sodium was initiated and well tolerated. The condition remained unchanged until now for $2 \mathrm{y}$. Family 3385: The index patient (III-1) presented at the age of $8 \mathrm{y}$ with exertional dyspnea and repeated syncope since the age of $3 \mathrm{y}$. On acute testing for pulmonary vascular vasoreactivity she did not respond to oxygen, nitric oxide, or inhaled iloprost. The girl was treated with home oxygen and phenprocoumon and remained in functional class II (NYHA) for $4 \mathrm{y}$ now. Both parents, both grandmothers, and two further members (II-5, III-3) had abnormal PASP responses to exercise. Her grandfather (I-1) had died due to lung cancer aged 69 before family screening was performed. Her grandfather I-3 had to be excluded due to inadequate Doppler signals during exercise. Her sister III-2 had a maximal PASP during exercise of $40 \mathrm{~mm} \mathrm{Hg}$. Pedigree 4133: This 10-y-old boy (IV-1) was first seen by a pediatric cardiologist at age $7 \mathrm{y}$ and complained of exercise intolerance over the last months. At first cardiac catheterization a $\mathrm{PH}$ and an anomalous pulmonary venous return of the left upper lobe into the superior cava vein was seen. On the basis of a small left-to-right shunt, a causal relationship seemed very unlikely and the diagnosis of PPH was made. A catheter 3 mo later (second opinion) revealed pulmonary artery pressures of 123/56/90 mm Hg, systemic arterial pressures of $81 / 96 / 59 \mathrm{~mm} \mathrm{Hg}$, and a pulmonary/systemic resistance ration of 1.53 . The main treatment consisted of i.v. prostacyclin (Flolan). Due to further deterioration, the boy was listed for heart-lung transplantation, which was conducted a few days after his ninth birthday. Both
$40 \mathrm{~mm} \mathrm{Hg}$ were classified as unknown. All other individuals were classified as normal.

Further statistical methods. Data are given as mean values \pm SD. All measurements of PASP were calculated as the means of three cardiac cycles. Groups were compared by the Mann-Whitney-Wilcoxon-test.

\section{RESULTS}

Clinical characterization of index patients with PPH. All 13 children [mean ( $\pm \mathrm{SD}$ ) age at diagnosis, $5.6 \pm 3.9 \mathrm{y}$; range, 6 mo to $13 \mathrm{y}$; female/male ratio, 1.2:1; 11 Germans, 2 Swiss] had a negative family history and had been initially classified as sporadic PPH. The mean time between the onset of symptoms and diagnosis by cardiac catheterization was $2.5 \pm 3.2 \mathrm{y}$ (range, 1 mo to $11 \mathrm{y}$ ). In Table 1, hemodynamic variables of index patients at the time of their diagnostic catheterization are summarized. All 13 children had severe $\mathrm{PH}$, with an at least 2-fold increase of mean pulmonary artery pressure and pulmonary vascular resistance, a normal pulmonary capillary wedge pressure, and a normal or reduced cardiac index. The hemodynamic response to vasodilators during cardiac catheterization could be assessed in 12 patients, with a significant response in $5(41.6 \%)$ if "responders" were defined as children who showed a decrease in mean pulmonary artery pressure and pulmonary vascular resistance exceeding 20\% from baseline on testing for acute pulmonary vasoreactivity using oxygen, nitric oxide, or prostanoids. If "responders" were defined according to the recommendation made during the last world congress on pulmonary hypertension in Venice 2003 as "a pulmonary artery pressure which almost normalized during vasoreactivity testing with a normal or increased cardiac output," 3 of the 12 patients $(25 \%)$ were responders. None of the children or their parents were affected or had a familial history of HHT. At familial assessment (mean, $0.9 \pm 0.9 \mathrm{y}$ after initial catheterization), one child had undergone lung transplantation, one had progressed to New York Heart Association (NYHA) class IV, and two had died due to right heart failure. One child (6735) died 3 mo after familial assessment. Two remained

parents and grandmothers were classified as AR members. His sisters had normal PASP values at rest. They were too young to perform supine bicycle exercise. Family 3421: The index patient (III-1) was born at term (weight, $2850 \mathrm{~g}$ ). Development within the first 8 mo was normal. At the age of 9 mo he developed intermittent abdominal pain, obstipation, motoric retardation, and recurrent respiratory infections. Diagnosis was made by cardiac catheterization and open lung biopsy at $3 \mathrm{y}$ of age. Although he was a nonresponder at initial testing for pulmonary vasoreactivity, his symptoms improved to inhaled iloprost and he remained stable. His father had a borderline PASP during exercise, his mother (II-6), aunt (II-3), and grandmother (I-2) were AR members. In his cousin (III-2), a pulmonary hypertension and lung hypoplasia was diagnosed perinatally. Family 3067: The index patient (IV-1) was born in wk 33 by cesarean section due to gestosis. At d 2 he developed an intestinal perforation most likely because of the prematurity. Further assessment aged 7 mo revealed a PH and markedly elevated serum noradrenaline levels. Second cardiac catheterization 6 mo later showed a significant improvement of all hemodynamic parameters. A manifest PH was suspected in his father due to an abnormal PASP at rest and during exercise. His mother, grandmother (II-3), grandfather (II-4), and aunt (III-1) were classified as AR members. In relatives II-5 and III-4, the abnormal PASP response to exercise was possibly due to systemic arterial hypertension. 
Table 1. Clinical data of the 13 index patients at diagnosis by right heart catheterization (hc)

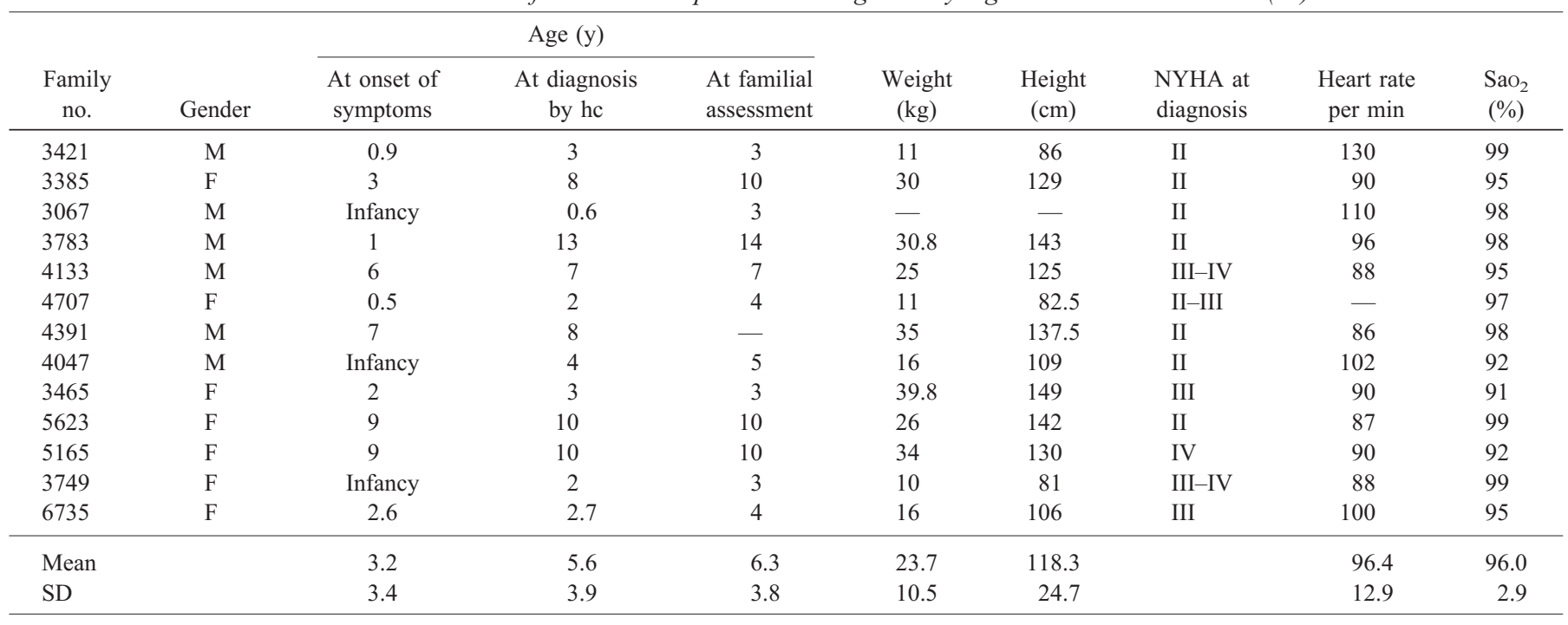

$\mathrm{SaO}_{2}$, oxygen saturation; PASP, pulmonary artery systolic pressure; PADP, pulmonary artery diastolic pressure; PAMP, pulmonary artery mean pressure; PCWP, pulmonary capillary wedge pressure; SASP, systemic arterial systolic pressure; SADP, systemic arterial diastolic pressure; CI, cardiac index; PVRI, pulmonary vascular resistance index; Rp/Rs, pulmonary/systemic resistance ratio.

stable and six had an immediate and significant decrease $(>20 \%)$ in pulmonary artery pressure and pulmonary vascular resistance index during therapy or revealed a subjective improvement in symptoms and physical abilities.

Mutation analysis. Mutations of the $B M P R 2$ gene could not be found in any of the 13 children and the parents. In two children (families 5779, 6735), a polymorphism of exon 12 (R937R) was documented. Larger deletions were excluded by Southern blot analysis in all index patients.

Familial assessment. In 6 of the 13 families, 57 further relatives were assessed clinically. Blood samples were obtained for genetic linkage analysis. The pedigrees of these families are shown in Figures 1 and 2. In two families, manifest PH was suspected in one further member. In a cousin (III-2) of the index patient of family 3421, PH was diagnosed in the neonatal period by echocardiography and confirmed by right heart catheterization. Lung hypoplasia was suggested after chest $\mathrm{x}$-ray and lung functions tests. Therefore, this child was not classified as PPH patient. Genetic assessment could not be performed yet. In family 3067 , the 23 -y-old father (III-2) of the index patient (IV-1) showed echocardiographically an elevated PASP at rest $(48 \mathrm{~mm} \mathrm{Hg})$ and during exercise $(84 \mathrm{~mm} \mathrm{Hg})$, enlarged right heart chambers (four chamber view minor 4.1 $\mathrm{cm}$, parasternal long axis: $4.5 \mathrm{~cm}$, indexed $2.1 \mathrm{~cm} / \mathrm{m}^{2}$ ) without further abnormalities. He was not known to have any heart or lung disease before. The patient died in a car accident before further examinations could be performed to confirm or exclude $\mathrm{PPH}$.

In all families at least one relative $(n=26)$ showed an abnormal PASP increase during exercise (from $22 \pm 5$ to $55 \pm$ $12 \mathrm{~mm} \mathrm{Hg}$ ) without secondary reasons. Eleven further family members had normal values both at rest and during exercise $(20 \pm 4$ to $35 \pm 3 \mathrm{~mm} \mathrm{Hg})$. There were no significant differences in age, weight, height, or hemodynamic parameters between normal and abnormal responders (Table 2). In five additional abnormal responders, secondary reasons could not be excluded: in three relatives the pathologic PASP response was associated with abnormal systemic blood pressures (mean, 220/110 mm Hg) during exercise, in one subject with dilated cardiomyopathy and in another with coronary artery disease. Thirteen relatives were excluded due to inadequate Doppler
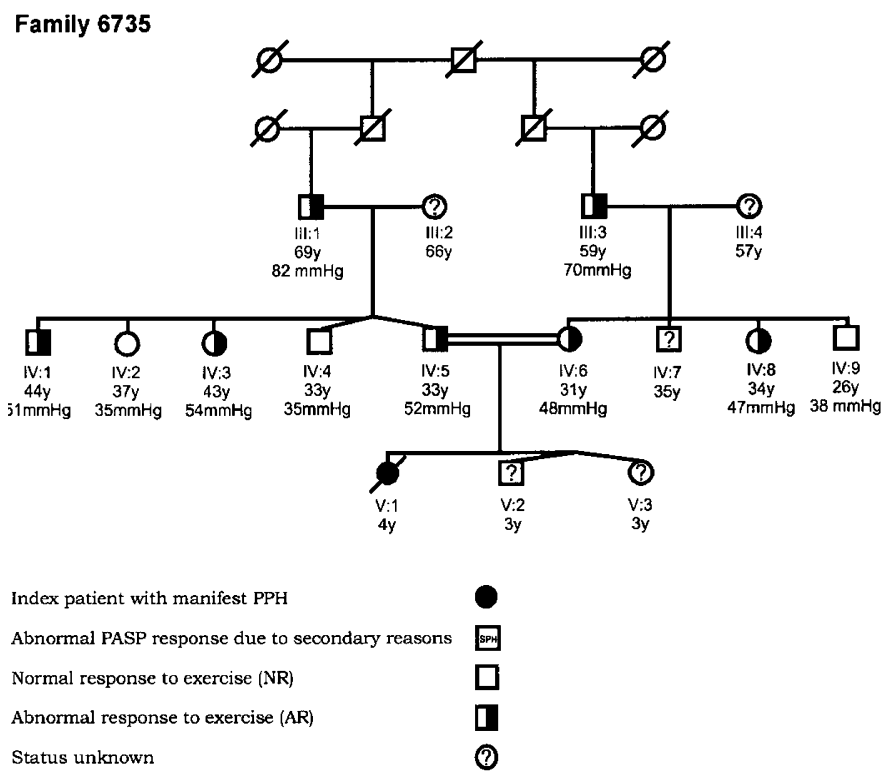

Maximal PASP at exercise are given in $\mathrm{mmHg}$

Figure 2. Family 6735: In the index patient $(\mathrm{V}: 1)$ of this consanguineous family, an idiopathic thrombocytopenia $\left(7 \times 10^{2}\right.$ thrombocytes/L) and a severe $\mathrm{PH}$ was diagnosed in the context of an assessment due to respiratory infection at age $2.5 \mathrm{y}$. At that time, she had only little cardiopulmonary symptoms. In the right heart catheterization, which was performed in an specialized university center for PH, the PA pressures were almost as high as the systemic pressures. At the age of $4 \mathrm{y}$, the patient was admitted to the hospital due to shortness of breath and died $24 \mathrm{~h}$ later. The parents refused an autopsy. In the family assessment, both parents and family members of both sides (III-1, III-3, IV-1, IV-3, IV-8) revealed high PASP response to exercise and/or hypoxia. None of them had cardiopulmonary symptoms. 
Table 1. Clinical data of the 13 index patients at diagnosis by right heart catheterization (hc) (continued)

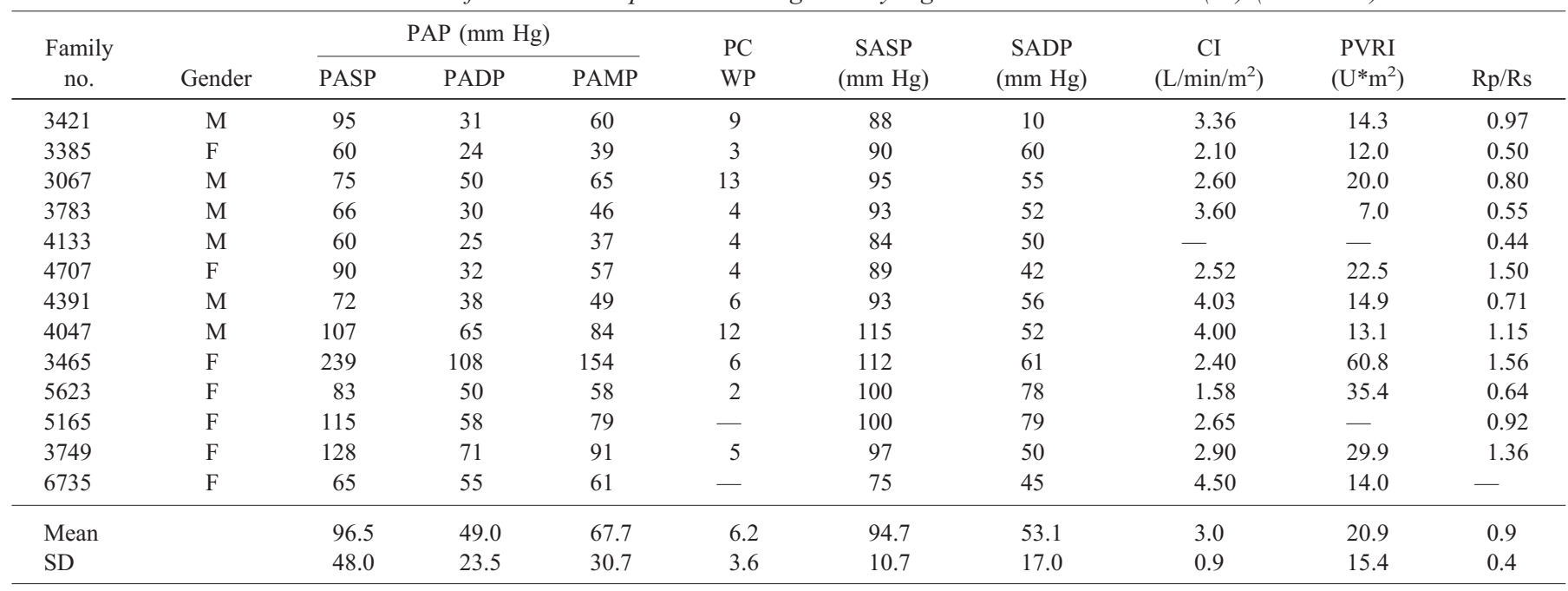

$\mathrm{SaO}_{2}$, oxygen saturation; PASP, pulmonary artery systolic pressure; PADP, pulmonary artery diastolic pressure; PAMP, pulmonary artery mean pressure; PCWP, pulmonary capillary wedge pressure; SASP, systemic arterial systolic pressure; SADP, systemic arterial diastolic pressure; CI, cardiac index; PVRI, pulmonary vascular resistance index; Rp/Rs, pulmonary/systemic resistance ratio.

signals $(n=6)$ or inability to perform supine bicycle exercise $(n=5)$ and 2 members with normal PASP values at rest and a maximal PASP of $40 \mathrm{~mm} \mathrm{Hg}$ were classified as status unknown because their values were borderline.

Control group. Eighty-six control subjects (51 females) with a mean age of $27 \pm 10 \mathrm{y}$ (range, 13-78 y) and a mean PASP at rest of $21 \pm 5 \mathrm{~mm} \mathrm{Hg}$ were assessed. Eight of 86 subjects (9.3\%, all female) had an exaggerated PASP response to exercise (from $25 \pm 5$ to $53 \pm 4 \mathrm{~mm} \mathrm{Hg}$ ) without secondary reasons. The high PASP values were already seen at low workloads of $50-75 \mathrm{~W}$, whereas 78 control subjects did not exceed $40 \mathrm{~mm} \mathrm{Hg}$ even at high workloads up to $200 \mathrm{~W}$. There was a significantly higher percentage of individuals with an abnormal PASP response to exercise (hereafter called "AR members") among the relatives of the children with $\mathrm{PPH}$ $(26 / 37=72 \%)$ than in the controls $(8 / 86=9.3 \%, p<0.0001)$.

Pedigree analysis. In all six families, abnormal PASP response was documented in both parents of the index patients and/or in both branches of their family. Under a model of dominant inheritance, assuming that all carriers of the mutation will be AR members, we expect that approximately 6 of the 12 parents show an AR status. The observed number of AR parents is significantly higher $(11 / 12, p<0.05)$. Moreover, this is still very conservative, inasmuch as the only NR parent happens to be the mother of a questionable case (family 3421, III-2). Hence, rather than a dominant model, a recessive mode of inheritance seems to be the most plausible model for the majority of assessed families. In this model, affected individuals have mutations on both alleles, whereas parents are heterozygous for the PPH mutation and therefore express an "AR" phenotype.

Linkage analysis. The LOD scores for 12q13 (ALK-1 region) and 2q31-33 (PPH1/PPH2 region) are shown in Tables 3 and 4. There was no evidence for linkage to the PPH1 (BMPR2) region in five of the six families $(3067,4133,3421$, $3783,6735)$. All pairwise cumulative LOD scores were nega- tive in the dominant model (Table 3 ) and also in the recessive model (Table 4). There was no linkage to the ALK1 region in these families.

\section{DISCUSSION}

Previous studies on the genetic background of PPH (9-12) have lead to the suggestion that sporadic and familial forms of PPH in adults share a common genetic basis. However, these studies did not assess the occurrence of BMPR2 mutations in children, in particular, although substantial clinical differences have been observed between adults and children (3-5). This is the first study performing a systematic genetic and clinical family screening in children with apparently sporadic PPH. Because none of the 13 assessed children had a BMPR2 mutation or a history of HHT, this study suggests that in a proportion of IPPH cases the disease may have a different genetic background than adults, not related to changes in the $B M P R 2$ or $A L K 1$ gene. The clinical assessment of the family members and pedigree analysis indicate that IPPH may be caused by a yet unknown gene or genes and may have a recessive rather than a dominant transmission in a proportion of cases.

Different genotype in infantile PPH. Most IPPH cases described previously $(3-5,12)$ appeared as sporadic disease. Thomson et al. (12) examined 50 patients aged 7-61 with sporadic PPH for BMPR2 mutations (12). They identified $B M P R 2$ mutations in 13 adults aged $>23 \mathrm{y}$ but not in children. Newman et al. (22) described a large family with PPH and a $B M P R 2$ mutation, in which the youngest patient was $10 \mathrm{y}$ old. Apart from this case, only two BMPR2 mutations - both deletions - have been described in children $(13,14)$.

We excluded BMPR2 deletions in our patients by Southern blot and microsatellite analysis. Furthermore, we found no evidence for point mutations in the $B M P R 2$ gene, neither by mutation scanning, nor by haplotyping, as multipoint LOD 
Table 2. Mean workload, cardiac output, maximal rate-pressure product, heart rate, and percentage of age-predicted heart rate

\begin{tabular}{|c|c|c|c|}
\hline & $\begin{array}{c}\text { AR members } \\
n=17\end{array}$ & $\begin{array}{c}\text { NR members } \\
n=8\end{array}$ & $p$ Value \\
\hline Gender & $5 \mathrm{~m}, 12 \mathrm{f}$ & $6 \mathrm{~m}, 2 \mathrm{f}$ & \\
\hline Age (y) & $44 \pm 15$ & $39 \pm 22$ & 0.47 \\
\hline Weight (kg) & $69 \pm 13$ & $68 \pm 18$ & 0.88 \\
\hline Height $(\mathrm{cm})$ & $167 \pm 7$ & $166 \pm 14$ & 0.52 \\
\hline \multicolumn{4}{|l|}{ Echo } \\
\hline PASP rest $(\mathrm{mm} \mathrm{Hg})$ & $22 \pm 4$ & $19 \pm 4$ & 0.045 \\
\hline PASP max (mm Hg) & $52 \pm 10$ & $36 \pm 4$ & $<0.001$ \\
\hline$\Delta$ PASP $(\mathrm{mm} \mathrm{Hg})$ & $30 \pm 9$ & $17 \pm 6$ & $<0.001$ \\
\hline \multicolumn{4}{|l|}{ At maximal exercise } \\
\hline Workload (W) & $128 \pm 49$ & $149 \pm 52$ & 0.33 \\
\hline Cardiac output (L/min) & $9.9 \pm 3$ & $10.7 \pm 4$ & 0.58 \\
\hline $\begin{array}{l}\text { Rate-pressure product (mm } \\
\mathrm{Hg} / \mathrm{min})\end{array}$ & $26908 \pm 5997$ & $29402 \pm 7098$ & 0.37 \\
\hline Heart rate $(\mathrm{bpm})$ & $147 \pm 23$ & $154 \pm 17$ & 0.51 \\
\hline $\begin{array}{l}\text { Percentage of age-predicted } \\
\text { maximal heart rate }(\%)\end{array}$ & $84 \pm 12$ & $86 \pm 11$ & 0.76 \\
\hline Stroke volume (mL) & $66 \pm 16$ & $70 \pm 21$ & 0.64 \\
\hline \multicolumn{4}{|l|}{ At maximal PASP } \\
\hline Workload (W) & $113 \pm 44$ & $124 \pm 48$ & 0.60 \\
\hline Cardiac output (L/min) & $7.3 \pm 2$ & $8.3 \pm 3$ & 0.37 \\
\hline $\begin{array}{l}\text { Rate-pressure product (mm } \\
\mathrm{Hg} / \mathrm{min} \text { ) }\end{array}$ & $24417 \pm 5564$ & $25849 \pm 7708$ & 0.61 \\
\hline Heart rate (bpm) & $137 \pm 23$ & $143 \pm 21$ & 0.59 \\
\hline $\begin{array}{l}\text { Percentage of age-predicted } \\
\text { maximal heart rate }(\%)\end{array}$ & $64 \pm 23$ & $71 \pm 33$ & 0.74 \\
\hline Stroke volume (mL) & $53 \pm 13$ & $56 \pm 17$ & 0.65 \\
\hline
\end{tabular}

All values are mean $\pm \mathrm{SD}$. AR members, abnormal PASP response to exercise; NR members, normal PASP response to exercise; PASP, pulmonary artery systolic pressure; $\triangle \mathrm{PASP}$, difference between maximal and rest PASP.

scores at the BMPR2 locus were negative in all six families assessed by linkage analysis. Although, it should be noted that in our smaller families the LOD scores did not reach the threshold for exclusion. Thus, it cannot be excluded that in a single case, a trait-causing BMPR2 mutation in a noncoding region remained undetected. Likewise, there was also no linkage to the $\mathrm{PPH} 2$ locus.

A previous study on HHT has shown that a PPH-like phenotype can occur in children carrying an ALK1 mutation (14). Characteristic for this type of infantile disease is the positive family history of HHT. All our patients had a negative family history for HHT. There was no linkage to the ALKI locus.

Mode of inheritance. All patients of this study had a negative family history for $\mathrm{PH}$ and initially no further members with confirmed manifest PPH. However, through the clinical screening assessment we identified two members with manifest PH coming from two families $(3067,3421)$. In these families an autosomal dominant mode of inheritance cannot be excluded. Interestingly, in all assessed families an abnormal PASP response to exercise was detected in relatives of both branches. The AR status occurred in $72 \%$ of relatives but only in $9.3 \%$ of controls. In families with adult PPH, an abnormal PASP response to exercise indicated a carrier status for a $\mathrm{PPH}$ mutation (15-17). If this is true also for relatives of children with PPH, it implies that both parents and/or relatives from both branches of the family are heterozygous mutation carriers. Although the families assessed here were not large enough for a formal segregation analysis, our data suggest that IPPH- or at least a proportion of cases - might have an autosomal recessive mode of inheritance caused by a mutation in a yet unknown gene(s).

Alternatively, one could hypothesize that these children are homozygous for dominant (undetected) BMPR2 mutations. This alternative explanation is unlikely, considering the high sensitivity of the method used for mutation screening, the negative LOD scores, and the fact that homozygous mutations in the BMPR2 gene have been shown to be lethal in mice (23). Another alternative explanation, presuming that these young patients will be sporadic cases with a de novo mutation in an unknown gene, is also not very plausible, as it does not provide an explanation for the high number of parents and relatives with an abnormal PASP response to exercise. The most striking hallmark of recessive inheritance is the occurrence of affected children born to consanguineous parents. Family 6735 is an example of such a consanguineous family. It is very noteworthy, that another family with two affected siblings (aged 6 and $10 \mathrm{y}$ ) born to consanguineous parents has recently been described (24). These observations strongly support the hypothesis that - at least in some cases-IPPH may have a recessive mode of inheritance. This suggests that IPPH has a different genetic background compared with adult PPH. On the other hand, it might also be possible that a proportion of sporadic adult patients share a similar genetic background as children and have a recessive or dominant-acting mutation in a yet unknown IPPH-related gene.

Phenotypic differences. Little information exists regarding clinical characterization in PPH of children (25). This might be due to the fact that IPPH is itself very rare. We estimate that in Germany about five children are diagnosed with PPH annually. The clinical data of the patients reported in this study support the previously described different phenotype of IPPH (3-5). All infants presented with severe symptoms at initial assessment like dyspnea, syncope, or physical retardation. The index patient of family 5165 had been misdiagnosed over $12 \mathrm{mo}$ and was thought to have epilepsy until she proceeded into cardiopulmonary arrest and had to be resuscitated. In all 12 index patients, pulmonary artery pressure and pulmonary vascular resistance were markedly elevated and succeeded systemic pressure in some cases, as described in children assessed by Barst et al. (4). Furthermore, the gender distribution in IPPH is more uniform (female/male ratio 1.2:1) than in adults [female/ male ratio 1.7:1 (2)] as described before (25). The fact that most parents in our study were found to have an AR status does not imply that all individuals in the general population expressing an abnormal PASP response to exercise are heterozygous carriers of IPPH mutations. The AR status is a rather unspecific finding based on a large spectrum of causes. An example of another AR-associated trait is the susceptibility to high-altitude pulmonary edema (20). Athletes had PASP values of $>40 \mathrm{~mm} \mathrm{Hg}$ in higher workloads (above 175-200 W). The abnormal PASP response to exercise in the family members of children with PPH occurred already at low workloads (50-125 W) (26). 
Table 3. LOD scores for dominant model at recombination distance $\theta$

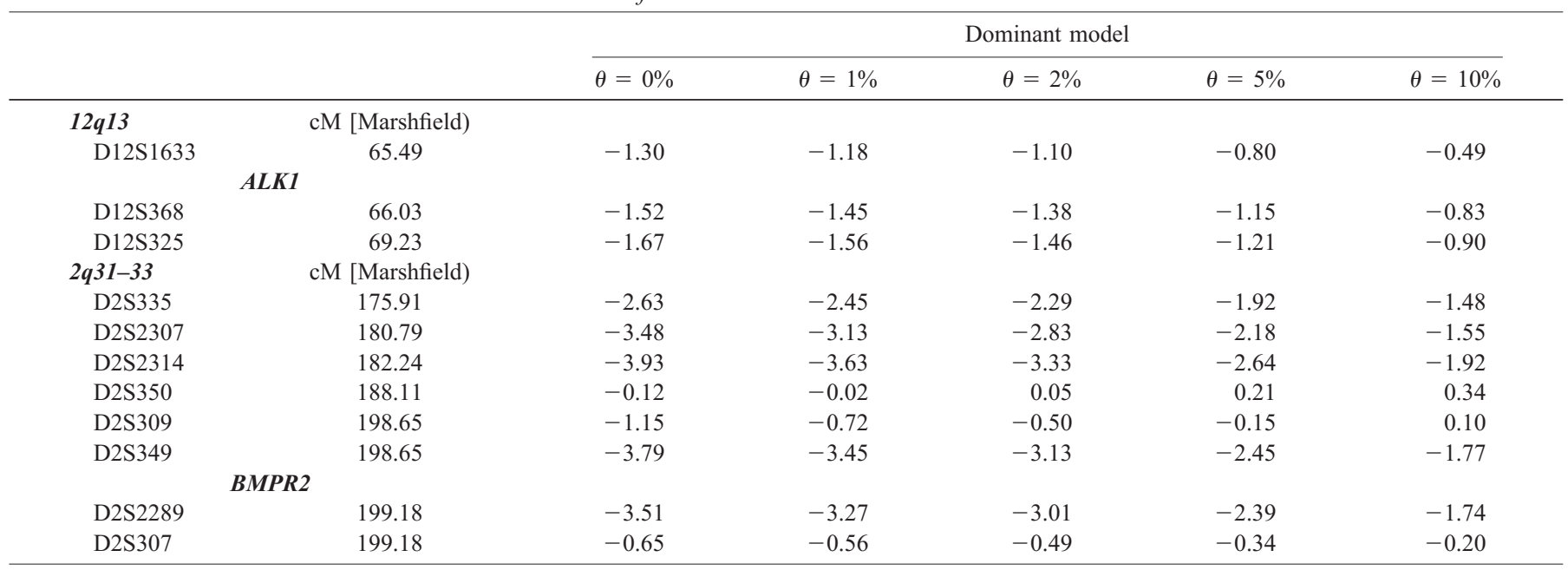

Pairwise cumulate LOD scores were obtained from six families with iPPH; 12q13: ALK1-linked markers, 2q31-33: PPH2/BMPR2-linked markers.

Table 4. $L O D$ scores for recessive model at recombination distance $\theta$

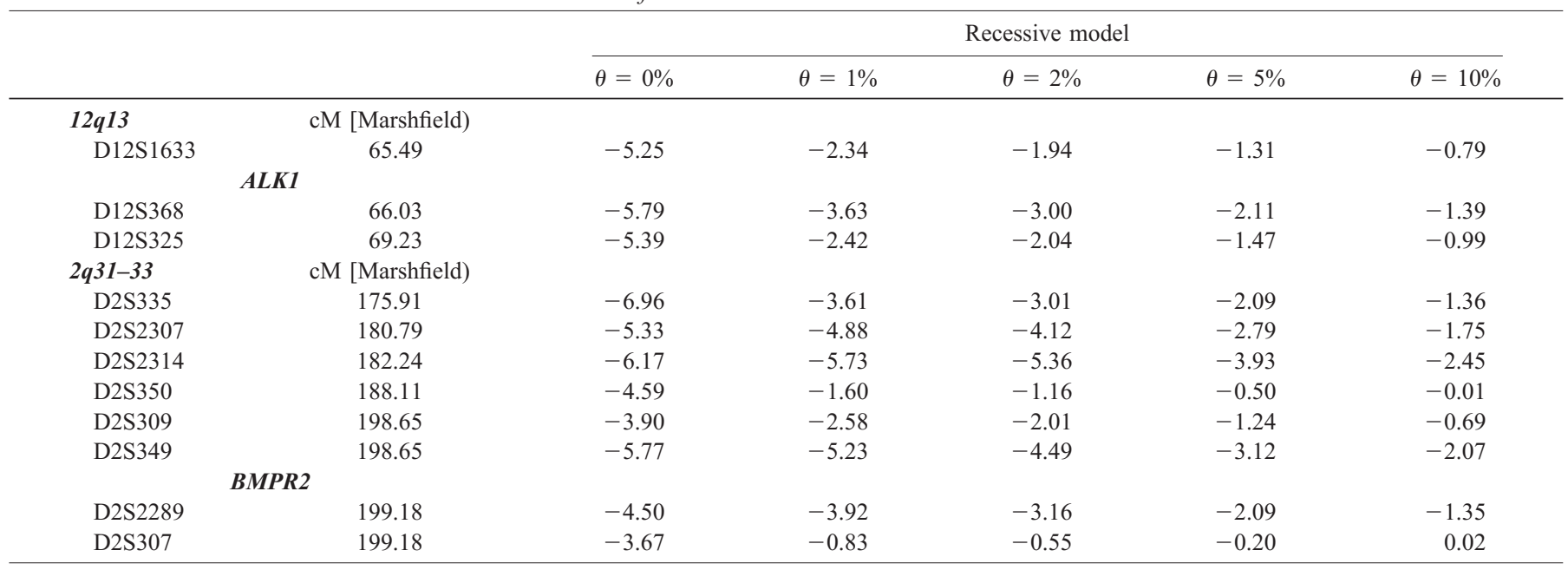

Pairwise cumulate LOD scores were obtained from six families with iPPH; 12q13: ALK1-linked markers, 2q31-33: PPH2/BMPR2-linked markers.

\section{CONCLUSIONS}

Our data indicate that there are many aspects that distinguish IPPH from the adult form of PPH. The main differences are as follows: 1) All our patients with IPPH showed a different phenotype than usually found in adults with PPH. Not only the age at onset, but also the occurrence of extremely high (often suprasystemic) pulmonary pressures and the significantly reduced life expectancy are characteristic for the infantile form. Further studies on larger numbers of patients will be required to identify further characteristic phenotypical aspects of IPPH. 2) In IPPH families, the index patient is a child. In these families, adult relatives with manifest PPH seem to be an exception, whereas other affected children are occasionally found. In contrast, familial adult PPH is characterized by a substantial number of affected adult relatives $(1,11,14,16,17,22)$. There are few reports on young affected children in families with adult index patients. 3) We found no relationship between the disease affecting the children of our study population and any of the currently known or postulated genes involved in autosomal dominant (adult) PPH. 4) On the basis of the unusually high number of relatives with an abnormal response to exercise and the occurrence of PPH in children born to consanguineous parents, we speculate that the mode of inheritance may be recessive in a proportion of cases. We therefore conclude that IPPH is a separate form of PPH in most cases. In a minority of cases, PH is HHT related, whereas in some other cases it is caused by deletions in the BMPR2 gene. The data imply the existence of a new locus that affects PASP response to exercise if mutated in one allele and produces the phenotype of IPPH if both copies are affected. Future research would likely include a genome scan on the IPPH families.

Acknowledgments. The authors thank all patients, their parents, and their relatives who participated and made such important contribution to the success of this study. We also thank all control subjects for their support and we acknowledge all clinicians and colleagues who provided suggestions and informations for the patients described, in particular, Dr. Fasnacht, University of Zürich, Christine Fischer, and Matthias Rindermann. We thank William Nichols and Michael W. Pauciulo for 
his contribution to the validation of DHPLC. Southern blot probes were kindly provided by Prof. R. Trembath, Leicester, UK. For critical review of the manuscript we thank PD Dr. Kuecherer.

\section{REFERENCES}

1. Loyd JE, Butler MG, Foroud TM, Conneally PM, Phillips III JA, Newman JH 1995 Genetic anticipation and abnormal gender ratio at birth in familial primary pulmonary hypertension. Am J Respir Crit Care Med 152:93-97

2. Rich S, Dantzker DR, Ayres SM, Bergofsky EH, Brundage BH, Detre KM, Fishman AP, Goldring RM, Groves BM, Koerner SK, Levy PC, Reid LM, Vreim CE, Williams GW 1987 Primary pulmonary hypertension. A national prospective study. Ann Intern Med 107:216-223

3. Haworth SG 1998 Primary pulmonary hypertension in childhood. Arch Dis Child $79: 452-455$

4. Barst RJ 1987 Primary pulmonary hypertension in children. In: Rubin LJ, Rich S (eds). Primary Pulmonary Hypertension. Marcel Dekker, New York, pp 179-225

5. Barst RJ, Maislin G, Fishman AP 1999 Vasodilator therapy for primary pulmonary hypertension in children. Circulation 99:1197-1208

6. D'Alonzo GE, Barst RJ, Ayres SM, Bergofsky EH, Brundage BH, Detre KM, Fishman AP, Goldring RM, Groves BM, Kernis JT, Levy PS, Pietra GG, Reid LM, Reeves JT, Rich S, Vreim CE, Williams GWm Wu M 1991 Survival in patients with primary pulmonary hypertension. Results from a national prospective registry. Ann Intern Med 115:343-349

7. Yamaki S, Wagenvoort CA 1985 Comparison of primary plexogenic arteriopathy in adults and children. A morphometric study in 40 patients. Br Heart J 54:428 434

8. Rich S, Kaufmann E, Levy PS 1992 The effect of high doses of calcium-channel blockers on survival in primary pulmonary hypertension. N Engl J Med 327:76-81

9. Lane KB, Machado RD, Pauciulo MW, Thomson JR, Phillips III JA, Loyd JE, Nichols WC, Trembath RC 2000 Heterozygous germline mutations in BMPR2, encoding a TGF- beta receptor, cause familial primary pulmonary hypertension. Nat Genet 26:81-84

10. Machado RD, Pauciulo MW, Thomson JR, Lane KB, Morgan NV, Wheeler L, Phillips III JA, Newman J, Williams D, Galie N, Manes A, McNeil K, Yacoub M, Mikhail G, Rogers P, Corris P, Humbert M, Donnai D, Martensson G, Tranebjaerg L, Loyd JE, Trembath RC, Nichols WC 2001 BMPR2 haploinsufficiency as the inherited molecular mechanism for primary pulmonary hypertension. Am J Hum Genet 68:92-102

11. Deng Z, Morse JH, Slager SL, Cuervo N, Moore KJ, Venetos G, Kalachikov S, Cayanis E, Fischer SG, Barst RJ, Hodge SE, Knowles JA 2000 Familial primary pulmonary hypertension (gene PPH1) is caused by mutations in the bone morphogenetic protein receptor-II gene. Am J Hum Genet 67:737-744

12. Thomson JR, Machado RD, Pauciulo MW, Morgan NV, Humbert M, Elliott GC, Ward K, Yacoub M, Mikhail G, Rogers P, Newman J, Wheeler L, Higenbottam T, Gibbs JS, Egan J, Crozier A, Peacock A, Allcock R, Corris P, Loyd JE, Trembath RC,
Nichols WC 2000 Sporadic primary pulmonary hypertension is associated with germline mutations of the gene encoding BMPR-II, a receptor member of the TGF-beta family. J Med Genet 37:741-745

13. Kramer BW, Martin T, Henn W, Lal S, Speer CP 2000 Lung hypoplasia in a patient with del(2)(q33-q35) demonstrated by chromosome microdissection. Am J Med Genet 94:184-188

14. Trembath RC, Thomson JR, Machado RD, Morgan NV, Atkinson C, Winship I, Simonneau G, Galie N, Loyd JE, Humbert M, Nichols WC, Morrell NW, Berg J, Manes A, McGaughran J, Pauciulo M, Wheeler L 2001 Clinical and molecular genetic features of pulmonary hypertension in patients with hereditary hemorrhagic telangiectasia. N Engl J Med 345:325-334

15. Janssen B, Rindermann M, Barth U, Miltenberger-Miltenyi G, Mereles D, Abushi A, Seeger W, Kübler W, Bartram CR, Grünig E 2002 Linkage analysis in a large family with primary pulmonary hypertension: genetic heterogeneity and a second PPH locus on 2q31-32. Chest 121:54S-56S

16. Rindermann M, Grünig E, von Hippel A, Koehler R, Miltenberger-Miltenyi G, Mereles D, Arnold K, Pauciulo M, Nichols W, Olschewski H, Hoeper MM, Winkler J, Katus HA, Kübler W, Bartram CR, Janssen B 2003 Primary pulmonary hypertension may be a heterogeneous disease with a second locus on chromosome $2 \mathrm{q} 31$. J Am Coll Cardiol 12:2237-2244

17. Grünig E, Janssen B, Mereles D, Barth U, Borst MM, Vogt IR, Fischer C, Olschewski H, Kuecherer HF, Kübler W 2000 Abnormal pulmonary artery pressure response in asymptomatic carriers of primary pulmonary hypertension gene. Circulation 102:1145-1150

18. Rubin L 1993 ACCP consensus statement: primary pulmonary hypertension. Chest 104:236-250

19. Barst RJ 1986 Pharmacologically induced pulmonary vasodilatation in children and young adults with primary pulmonary hypertension. Chest 89:497-503

20. Grünig E, Mereles D, Hildebrandt W, Swenson ER, Kübler W, Kuecherer H, Bartsch P 2000 Stress Doppler echocardiography for identification of susceptibility to high altitude pulmonary edema. J Am Coll Cardiol 35:980-987

21. Lathrop GM, Lalouel JM, Julier C, Ott J 1984 Strategies for multilocus linkage analysis in humans. Proc Natl Acad Sci U S A 81:3443-3446

22. Newman JH, Wheeler L, Lane KB, Loyd E, Gaddipati R, Phillips III JA, Loyd JE 2001 Mutations in the gene for bone morphogenetic protein receptor II as a cause of primary pulmonary hypertension in a large kindred. N Engl J Med 5:319-324

23. Beppu H, Kawabata M, Hamamoto T, Chytil A, Minowa O, Noda T, Miyazono K 2000 BMP type II receptor is required for gastrulation and early development of mouse embryos. Dev Biol 221:249-258

24. Shanmugasundaram S 2002 Familial primary pulmonary hypertension. Indian Heart J 54:193-195

25. Sandoval J, Bauerle O, Gomez A, Palomar A, Martinez Guerra ML, Furuya ME 1995 Primary pulmonary hypertension in children: clinical characterisation and survival. J Am Coll Cardiol 25:466-474

26. Bossone E, Rubenfire M, Bach DS, Ricciardi M, Armstrong WF 1999 Range of tricuspid regurgitation velocity at rest and during exercise in normal adult men: implications for the diagnosis of pulmonary hypertension. J Am Coll Cardiol $33: 1662-1663$ 